\title{
Microstamp-Based Micromachining for Modulation of Growth of Cultured Neuronal Cells*
}

\begin{abstract}
Yuki TAKII**, Hirokazu KAJI***, Tomokazu MATSUE** and Matsuhiko NISHIZAWA***
The microcontact printing $(\mu \mathrm{CP})$ is a well-established method to pattern a material of interest using an elastomeric stamp. We have developed two techniques which assist the $\mu \mathrm{CP}$-based cell-patterning for the controlled growth guidance of cultured neuronal cells on substrates. (i) Contact-transfer of extracellular matrix (ECM) protein on a microelectrode array substrate was achieved by spatially designing the microstamp to allow printing proteins even on the surface having uneven structures, and the differentiated PC12 cells showed selective adhesion and growth in the pre-determined locations on the electrode array. (ii) Cell alignment onto the pre-patterned ECM protein was also succeeded by using the microstructured silicon wafer having a band array of microholes, and the placed PC12 cells extended their axons along the protein pattern. These researches were carried out with the objective to developing a cell-based device based on a cellular network.
\end{abstract}

Key Words: Biomicromachine, Surface Treatment, Microcontact Printing $(\mu \mathrm{CP})$, Poly(dimethylsiloxane) (PDMS), Microstamp, Microelectrode Array, Extracellular Matrix (ECM), Neuronal Cell, Cell Adhesion, Axonal Guidance

\section{Introduction}

Spatial control of cell adhesion and growth on substrates is an important theme in both investigation of fundamental cellular function and cell-based biodevices such as biosensors and neurocomputers. To date, surface modification with topographical and chemical techniques has been utilized to form a cellular micropattern ${ }^{(1)-(10)}$. Microcontact printing $(\mu \mathrm{CP})$ using an elastomeric stamp made of poly(dimethylsiloxane) (PDMS) was devised to print organic molecules by Whitesides group ${ }^{(1),(2)}$, which is based on the contact-transfer of the material of interest from the stamp only on the areas contacted by the stamp. The $\mu \mathrm{CP}$ has been recognized as a useful method to form a cellular pattern by stamping extracellular matrix (ECM) proteins on substrates.

Bioassays using cultured cells have been conventionally carried out for evaluating cytotoxic effects as

* Received 27th April, 2004 (No. 04-4098)

** Department of Biomolecular Engineering, Graduate School of Engineering, Tohoku University, 07Aramaki, Aoba, Sendai 980-8579, Japan

*** Department of Bioengineering and Robotics, Graduate School of Engineering, Tohoku University, 01Aramaki, Aoba, Sendai 980-8579, Japan.

E-mail: nishizawa@biomems.mech.tohoku.ac.jp an alternative to animal experiments. Also, cell-based bioassay for drug screening and environmental monitoring has evoked strong interest as a high throughput technique $^{(11)-(16)}$. Regardless of the detection method, most of the cellular assays have focused on the activity of individual cells. In addition to the single cell activity, the function of cell-cell networks, such as synaptic junctions should also be an important measure for drug analysis. We recently achieved the micropatterning of cardiac myocytes for the purpose of studying intercellular communication on a defined network level ${ }^{(17)-(19)}$. In order to obtain sophisticated information from electrogenic cells such as neuronal cells, it is necessary to place cells in predetermined locations and to guide their growth on the chip with defined shapes and sizes.

In this paper, we describe two techniques which assist the $\mu \mathrm{CP}$-based cell-patterning in the growth guidance of cultured neuronal cells on substrates. (i) Integration of a cellular network with the microelectrode array has been attempted. A few groups have already reported devices for the aligned printing of biomolecules onto microelectrode $\operatorname{arrays}^{(20)-(22)}$, while the used substrates are still troublesome for printing molecules mainly due to their surface nonuniformity. We have achieved contact-transfer of extracellular matrix (ECM) protein on the electrode array substrate by spatially designing the microstamp to allow 
printing proteins even on the surface having uneven structures, and the differentiated PC12 cells showed selective adhesion and growth in the pre-determined locations on the electrode array. (ii) Localized cell placement onto the pre-patterned ECM protein has been also succeeded by using the microstructured silicon wafer having a band array of microholes, and the placed PC12 cells extended their axons along the protein pattern.

\section{Experimental}

\subsection{Chemicals}

Fibronectin (FN) (from human plasma, Wako Pure Chemical Industries), laminin (LN) (Sigma), n-octadecyltriethoxysilane (Tokyo Kasei), poly(dimethylsiloxane) (PDMS) (KE-106, Shin-Etsu Chem. Co., Ltd.), polyimide (Toray), nerve growth factor (7 s NGF) (Gibco), fluo-3 AM (Molecular Probes) and all other chemicals were used as received.

\subsection{Fabrication of ITO microelectrode array}

The indium tin oxide (ITO)-based planar microelectrode array was fabricated by photolithography-based microfabrication technologies. First, ITO on a glass substrate was wet-etched with a solution consisting of (in vol\%) $36 \mathrm{HCl}, 36 \mathrm{H}_{2} \mathrm{O}$, and $28 \mathrm{HNO}_{3}$ to form a transparent conductive pattern, which was composed of 4 independent microelectrodes having a thickness of $0.1 \mu \mathrm{m}$. Secondly, the negative photosensitive polyimide was spincoated to form an insulating layer of $8 \mu \mathrm{m}$ thickness, followed by photo-etching by a standard procedure to expose the microelectrodes. The size of each microelectrode was $50 \times 50 \mu \mathrm{m}$, and the 4 microelectrodes were arranged in $2 \times 2$ arrays with an interpolar distance of $200 \mu \mathrm{m}$. Finaly, a glass ring was attached at the center of the substrate using silicon adhesive to form a culture chamber. Experimental details are discussed in the section of Results and Discussion.

\subsection{Fabrication of PDMS microstamp}

The PDMS microstamp was produced by photolithography and a molding technique as previously described $^{(14),(17)-(19)}$. Briefly, the liquid prepolymer of PDMS was poured over the template pattern $(17 \mu \mathrm{m}$ thick photoresist pattern on a glass plate) and cured at $100^{\circ} \mathrm{C}$ for $1 \mathrm{~h}$. The resulting thin PDMS stamp was cut into $5 \times 5 \mathrm{~mm}$ pieces, then stuck on a clean glass plate of the same size.

\subsection{Fabrication of microstructured silicon wafer}

The mask substrate for cell alignment was a band array of frustum cavities micromachined on a silicon wafer ${ }^{(15)}$. Briefly, a (100) silicon wafer (230 $\mu$ m thick; optically polished on both sides) was oxidized in a wet oxygen atmosphere at $1000^{\circ} \mathrm{C}$ for $10 \mathrm{~h}$ to produce a $1.5 \mu \mathrm{m}$ thick oxide layer. Array of rectangle windows were photolithographically prepared in the oxide layer to define the large openings of the miorocavities. The anisotropic etching in $25 \%\left(\mathrm{CH}_{3}\right)_{4} \mathrm{NOH}$ at $80^{\circ} \mathrm{C}$ was then carried out to form array of frustum-like cavities into the wafer.

\subsection{Pretreatment of ITO microelectrode array and PDMS stamp}

The hydrophobic pretreatmetnt of the microelectrode array was carried by silanization in $10 \mathrm{mM} n$ octadecyltriethoxysilane / benzene for $10 \mathrm{hrs}$, followed by a thorough rinse with pure benzene, ethanol, deionized water and drying.

The PDMS stamp was treated with $\mathrm{O}_{2}$ plasma to first make its surface hydrophilic, followed by application of a fibronectin (FN) aqueous solution $\left(2.8 \mathrm{mg} \mathrm{mL}^{-1}\right)$ or a laminin (LN) aqueous solution $\left(50 \mu \mathrm{g} \mathrm{mL}^{-1}\right)$ onto the stamp surface and then left for 20 min under ambient conditions.

\subsection{Cell cultures}

The stock PC12 cells were donated from the Cell Resource Center for Biomedical Research, Tohoku University, and kept in RPMI1640 medium (Gibco) supplemented with $10 \%$ fetal bovine serum (FBS) (Gibco), $50 \mu \mathrm{g}$ $\mathrm{mL}^{-1}$ penicillin (Gibco), and $50 \mu \mathrm{g} \mathrm{mL}^{-1}$ streptomycin (Gibco) in a $5 \% \mathrm{CO}_{2}$ incubator $^{(16)}$. The cells were seeded $\left(5 \times 10^{4}\right.$ cells $\left.\mathrm{mL}^{-1}\right)$ onto the patterned substrate and cultured in the medium containing $50 \mathrm{ng} \mathrm{mL}^{-1} 7 \mathrm{~s} \mathrm{NGF}$.

Chick dosal root ganglion (DRG) explants were cultured as previously described ${ }^{(10)}$. DRGs were obtained from 8-day-old chick embryos and placed on the patterned substrate and cultured in Dulbecco's modified eagle medium (DMEM) (Gibco) containing 10\% FBS, $50 \mu \mathrm{g}$ $\mathrm{mL}^{-1}$ penicillin, and $50 \mu \mathrm{g} \mathrm{mL}^{-1}$ streptomycin in the presence of $7 \mathrm{~s} \mathrm{NGF}\left(50 \mathrm{ng} \mathrm{mL}^{-1}\right)$.

\subsection{Intracellular $\mathrm{Ca}^{2+}$ imaging}

Intracellular $\mathrm{Ca}^{2+}$ imaging was performed using a Nipkow-type high-speed confocal microscopy system (CSU21, Yokogawa Electric Company). The cultured cells were loaded with $10 \mu \mathrm{M}$ fluo-3 AM for $30 \mathrm{~min}$ at $37^{\circ} \mathrm{C}$, and studied in a phosphate-buffered saline (PBS(+)) solution consisting of (in $\mathrm{mM}$ ) $0.90 \mathrm{CaCl}_{2}, 2.68 \mathrm{KCl}, 1.47$ $\mathrm{KH}_{2} \mathrm{PO}_{4}, 0.49 \mathrm{MgCl}_{2}, 136.9 \mathrm{NaCl}, 8.06 \mathrm{Na}_{2} \mathrm{HPO}_{4}, 5.55$ glucose, and 0.327 sodium pyruvate ( $\mathrm{pH} 7.4$ ). FBS was removed during the fluorescent measurements because it significantly increases the fluorescent backgrounds and downgrades the $\mathrm{S} / \mathrm{N}$ ratio. Cells were excited with a 488 $\mathrm{nm}$ argon laser, and fluorescence at $530 \mathrm{~nm}$ was detected with a digital CCD camera (HiSCA, C6790-81, Hamamatsu Photonics) through a barrier filter. Images were recorded on a computer and analyzed with Aquacosmos software (Hamamatsu Photonics).

\subsection{Electrical stimulation}

Electrical stimulation of a specific part of the cellular patterns was conducted using a capillary microelectrode or the ITO microelectrode plated on the substrate. The capillary electrode was fabricated by inserting a fine $\mathrm{Pt}$ wire into a PBS-filled glass capillary (tip diameter, $10 \mu \mathrm{m})^{(18)}$. A Current pulse was induced between the microelectrode 
and the other Pt wire placed in the culture chamber using an electronic stimulator (SEN-7203, Nihon Kohden) coupled with an isolator unit (SS-202J, Nihon Kohden).

\section{Results and Discussion}

\section{1 Micropatterning of neuronal cells on glass sub- strate}

Prior to the integration of cells on the microlelectrode array substrates, we carried out preliminary experiments to characterize fibronectin (FN) and laminin (LN), as the ink for the patterning of the PC12 cells and DRG neurons on the hydrophobic substrate. FN and LN are well-known ECM proteins, which generally promote the adhesion of mammalian cells ${ }^{(23)}$. Figure 1 shows the phase contrast micrographs of (a) the NGF-differentiated PC12 cells and (b) the DRG neurons cultured on the LN patterned substrates. In both cases, the protein printing was carried out by using the PDMS stamp having a grid pattern $(4 \mu \mathrm{m}$ line width, $25 \mu \mathrm{m}$ node size, $100 \mu \mathrm{m}$ node-node distance). The PC12 cell suspension $\left(5 \times 10^{4}\right.$ cells $\left.\mathrm{mL}^{-1}\right)$ was seeded on the patterned substrate and incubated for a week. In the case of the DRG neurons, the dissected ganglia were placed on the patterned substrate without dispersion and cultured for four days. As can be seen in Fig. 1, both cell types are visually forming cellular networks along the preformed protein patterns. It is worth noting that the LNpatterned substrate can control the adhesion and neurite outgrowth of both the PC12 cells and the DRGs, while the FN-patterned substrate served only for the DRGs (Data not shown). These results would be due to multiple biological functions of LN including neurite growth promotion $^{(24)}$. The cellular patterns prepared in this manner could be maintained for a few days without outgrowth in the serum containing culture medium after these patterns were visually formed.

Figure 2 shows the sequential $\mathrm{Ca}^{2+}$ fluorescence images of the DRG neurons cultured on the LN-patterned substrate. The arrow in the image indicates the point where the current pulse (amplitude: $0.3 \mathrm{~mA}$, duration: $150 \mu \mathrm{s})$ was externally applied using a capillary microelectrode. When the node part of the grid-structured DRGs was electrically stimulated (Fig. 2, $0 \mathrm{sec}$ ), the externally induced $\mathrm{Ca}^{2+}$ waves were observed. As can be seen in Fig. $2(6-18 \mathrm{sec}), \mathrm{Ca}^{2+}$ waves were propagated from the stimulated point along the axon in every direction. The velocity of the waves was approximately the same in every direction, ca. $15 \mu \mathrm{m} \mathrm{s}^{-1}$, the value being in agreement with that reported for the normal random culture of DRGs ${ }^{(25)}$. This result indicates that the geometric restriction by patterning would not have a significant influence on the fundamental features of these cells, such as the distribution of the $\mathrm{Ca}^{2+}$ store, endoplasmic reticulum.

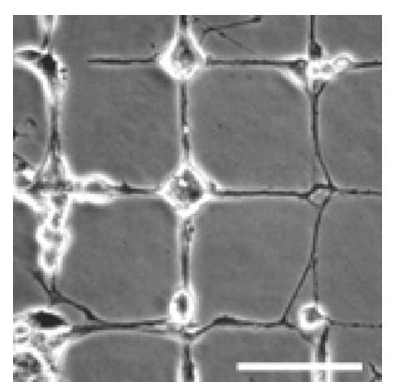

(a)

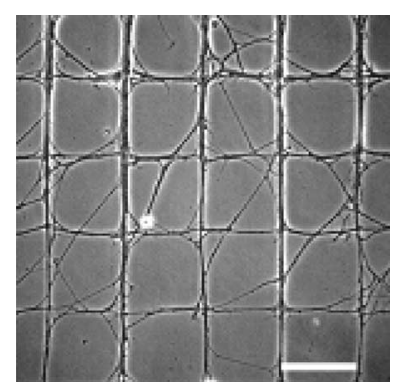

(b)
Fig. 1 Phase contrast micrographs of (a) the PC12 cells and (b) the DRG neurons cultured on the glass substrates, where the grid pattern ( $4 \mu \mathrm{m}$ line width, $25 \mu \mathrm{m}$ node size, $100 \mu \mathrm{m}$ node-node distance) of LN was pre-transferred by the PDMS microstamp. (Scale bars indicate $100 \mu \mathrm{m}$.)
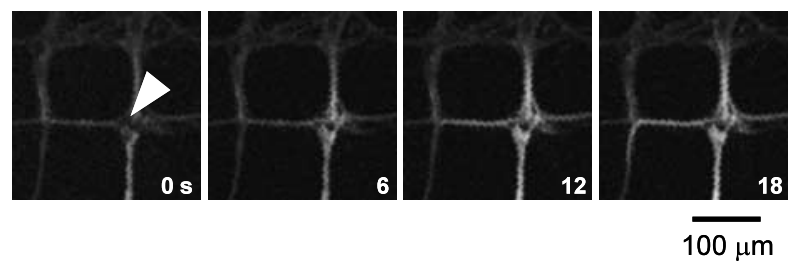

Fig. 2 Sequential confocal $\mathrm{Ca}^{2+}$ images of the grid patterned DRG neurons on the glass substrate. A Current pulse (amplitude: $0.3 \mathrm{~mA}$, duration: $150 \mu \mathrm{s}$ ) was applied to the arrowed point in the image using a capillary microelectrode.

\subsection{Integration of cellular network with microelec- trode array}

Figure 3 shows the micrographs of (a) the ITO-based microelectrode array and (b) the PDMS microstamp designed for printing ECM proteins onto the electrode array. We designed the alignment setup as shown in Fig. 3(c) and (d). The XYZ $\theta$ stage can be moved in the translational $(X, Y, Z)$ and rotary $(\theta)$ directions on a micron scale. The microelectrode array to be patterned is clamped above the stage, and the PDMS stamp inked with the ECM protein is put on the stage. The microscope objective is held above the transparent electrode array substrate, allowing both surfaces of the substrate and the stamp to be visualized, which enables us to align these separate patterns. After the inked stamp was pressed on the electrode array substrate with a force of ca. $10 \mathrm{~g} \mathrm{~cm}^{-2}$ for $1 \mathrm{~min}$, the substrate was lifted off and rinsed with phosphate-buffered saline (PBS).

Figure 4 (a) shows the phase contrast micrograph of the PC12 cells cultured on the LN-patterned microelectrode array. Before printing the LN, a hydrophobic pretreatment was carried out for the substrate surface. The microelectrode array substrate was made of glass-based material and optically transparent, which enables the pretreatment in the same way as glass plates and a variety of fluorescence measurement in the usual manner. It can be seen that the cells adhered and grew only on the 


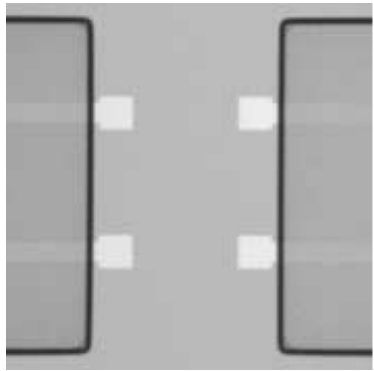

(a)

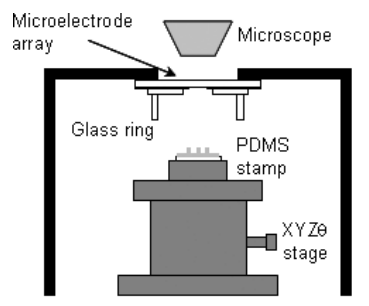

(c)

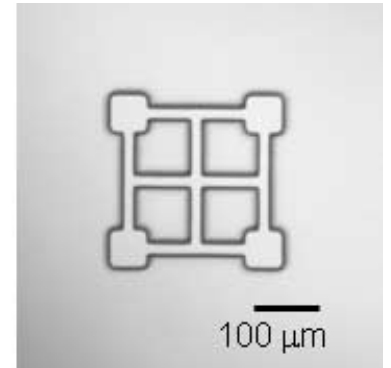

(b)

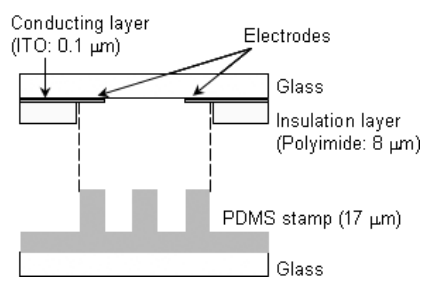

(d)
Fig. 3 Printing ECM proteins onto the microelectrode array. Micrographs of (a) the ITO microelectrode array and (b) the PDMS stamp designed for printing proteins aligned with the electrode patterns. (c) Schematic diagram of the setup for aligned microcontact printing. (d) Close-up of the electrode array and the stamp

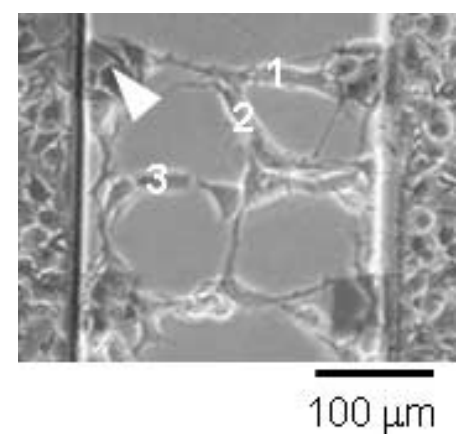

(a)
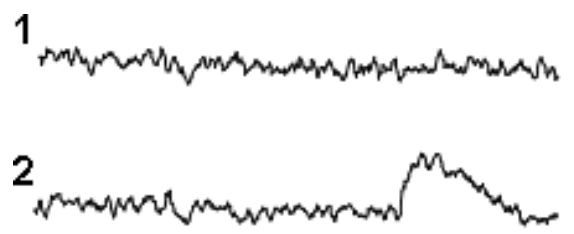

3

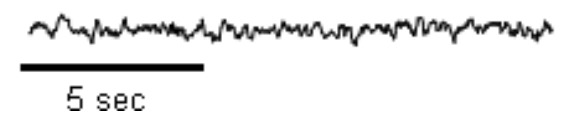

(b)

Fig. 4 (a) Phase contrast micrograph of the PC12 cells cultured on the LN-patterned electrode array. (b) Time course of fluorescence of intracellular $\mathrm{Ca}^{2+}$ measured at the points denoted in the image as $1-3$. Current pulses (amplitude: $0.3 \mathrm{~mA}$, duration: $150 \mu \mathrm{s}$, interval: $0.1 \mathrm{~s}$ ) were applied by the arrowed electrode during measurement.
LN-printed area, indicating that the PDMS stamp can be aligned and contacted to the substrate using the aligner shown in Fig. 3. In order to build such a pattern on the ITO microelectrode array, a few modifications were made to the stamp, as described in the experimental section. The PDMS stamp was produced using the photoresist template $(17 \mu \mathrm{m})$, which was much thicker than the insulation layer $(8 \mu \mathrm{m})$ of the microelectrode array, and the pattern of the stamp was limited within the area where the electrode and the glass surface were exposed.

Figure 4 (b) shows the time course of the fluorescence intensity, corresponding to the changes in the intracellular $\mathrm{Ca}^{2+}$ concentration. Data were taken at the points denoted in Fig. 4 (a) as 1, 2 and 3. The current pulses (amplitude: $0.3 \mathrm{~mA}$, duration: $150 \mu \mathrm{s}$, interval: $0.1 \mathrm{~s}$ ) were applied using one of the array electrodes marked by the white arrow during measurement. As can be seen in Fig. 4(b), the $\mathrm{Ca}^{2+}$ signal was observed at point 2 , while no signal was detected at points 1 and 3 . This result indicates that the visually-formed neuronal network seems insufficient to regulate the network functions such as synaptic transmission. Further studies should be needed to explore the physiochemical conditions that activate the cellular junctions. The present assembly with neuronal network would contribute to such basic researches on cellular science.

\subsection{Localized cell placement onto the pre- patterned ECM protein}

Figure 5 shows our strategy to align cells onto the limited area on the substrate. The ECM protein pattern is prepared by $\mu \mathrm{CP}$ in advance, and the silicon wafer having a band array of microholes is put on the substrate as to give vertical intersection of patterns of the proteins and micloholes. After the cells attach to the adhesive area, the
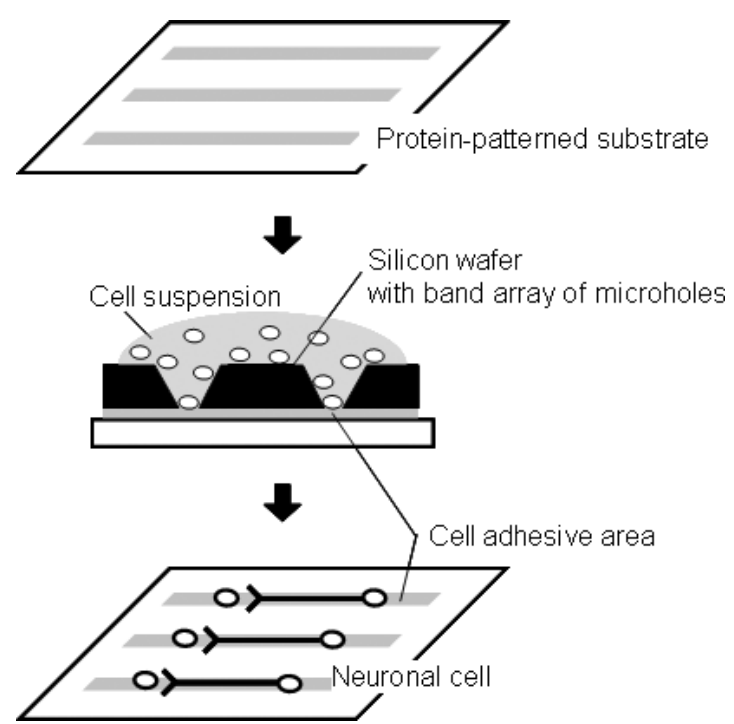

Fig. 5 Schematic outline of the cell alignment onto the pattern of ECM proteins by using the micromachined silicon wafer 


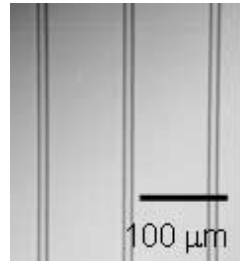

(a)

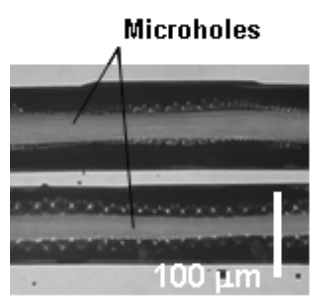

(c)

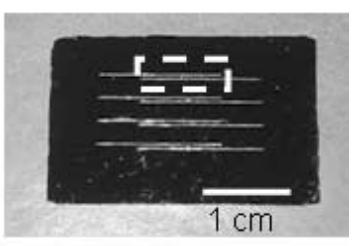

(b)

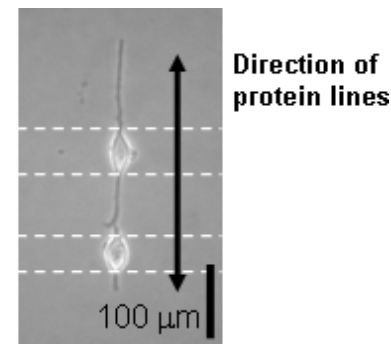

(d)
Fig. 6 Micrographs of (a) the PDMS stamp and (b) microstructured silicon wafer having a band array of microholes. (c) Close-up of the enclosed area denoted in the image (b). (d) Phase contrast micrograph of the PC12 cells cultured on the LN-patterned substrate. The dotted-lines indicate the area where the microholes were located.

silicon wafer is removed from the substrate. Because the cell body is located at the point of the intersection, the axonal outgrowth from the predetermined position can be guided along the remaining protein pattern.

Figure 6(a)-(c) show the PDMS stamp to make a band array of the 10- $\mu \mathrm{m}$-width ECM protein and silicon wafer having frustum-like microholes. The LN micropattern was printed on a hydrophobic glass substrate to be aligned with the edge of the substrate. By using the substrate edge as a guide ${ }^{(19)}$, the silicon wafer was put on the substrate. Figure 6 (d) shows the PC12 cells cultured for 3 days after the silicon wafer was removed from the substrate. It can be seen that the axons are extending along the LN pattern from the cell body which is immobilized at the position where the LN lines and microholes intersected.

\section{Conclusion}

We have described two techniques which assist the $\mu \mathrm{CP}$-based cell-patterning in the growth guidance of cultured neuronal cells on substrates. First, the microstamp was spatially designed to allow printing proteins on the uneven substrate for integrating a cellular network with the microelectrode array. Next, the silicon wafer having a band array of microholes was utilized to locally place the cells on the pre-patterned ECM proteins for the axonal guidance from the predetermined position. The present techniques would provide a way to form a defined neuronal network on substrates.

\section{Acknowledgements}

This research was partially supported by Grant-in-
Aid for Young Scientists (A), 15681008 from the Ministry of Education, Science, Sports and Culture.

\section{References}

( 1 ) Xia, Y. and Whitesides, G.M., Soft Lithography, Angew. Chem. Int. Ed., Vol.37 (1998), pp.550-575.

( 2 ) Kane, R.S., Takayama, S., Ostuni, E., Ingber, D.E. and Whitesides, G.M., Patterning Proteins and Cells Using Soft Lithography, Biomaterials, Vol.20 (1999), pp.2363-2376.

( 3 ) Folch, A. and Toner, M., Microengineering of Cellular Interactions, Annu. Rev. Biomed. Eng., Vol.2 (2000), pp.227-256.

(4) Branch, D.W., Wheeler, B.C., Brewer, G.J. and Leckband, D.E., Long-Term Maintenance of Patterns of Hippocampal Pyramidal Cells on Substrates of Polyethylene Glycol and Microstamped Polylysine, IEEE Trans. Biomed. Eng., Vol.47 (2000), pp.290-300.

( 5 ) Kam, L., Shain, W., Turner, J.N. and Bizios, R., Axonal Outgrowth of Hippocampal Neurons on Micro-Scale Networks of Polylysine-Conjugated Laminin, Biomaterials, Vol.22 (2001), pp.1049-1054.

(6) Ito, Y., Surface Micropatterning to Regulate Cell Functions, Biomaterials, Vol.20 (1999), pp.2333-2342.

(7) Yamato, M., Konno, C., Utsumi, M., Kikuchi, A. and Okano, T., Thermally Responsive Polymer-Grafted Surfaces Facilitate Patterned Cell Seeding and CoCulture, Biomaterials, Vol.23 (2002), pp.561-567.

( 8 ) Corey, J.M., Wheeler, B.C. and Brewer, G.J., Micrometer Resolution Silane-Based Patterning of Hippocampal Neurons: Critical Variables in Photoresist and Laser Ablation Processes for Substrate Fabrication, IEEE Trans. Biomed. Eng., Vol.43 (1996), pp.944-955.

(9) Entcheva, E. and Bien, H., Tension Development and Nuclear Eccentricity in Topographically Controlled Cardiac Syncytium, Biomed. Microdevices, Vol.5 (2003), pp.163-168.

(10) Kaji, H., Kanada, M., Oyamatsu, D., Matsue, T. and Nishizawa, M., Microelectrochemical Approach to Induce Local Cell Adhesion and Growth on Substrates, Langmuir, Vol.20 (2004), pp.16-19.

(11) González, J.E., Oades, K., Leychkis, Y., Harrotunian, A. and Negulescu, P.A., Cell-Based Assays and Instrumentation for Screening Ion-Channel Targets, Drug Discov. Today, Vol.4 (1999), pp.431-439.

(12) Bhadriraju, K. and Chen, C.S., Engineering Cellular Microenvironments to Improve Cell-Based Drug Testing, Drug Discovery Today, Vol.7 (2002), pp.612-620.

(13) Offenhäusser, A. and Knoll, W., Cell-Transistor Hybrid Systems and Their Potential Applications, Trends Biotechnol., Vol.19 (2001), pp.62-66.

(14) Nishizawa, M., Takoh, K. and Matsue, T., Micropatterning of HeLa Cells on Glass Substrates and Evaluation of Respiratory Activity Using Microelectrodes, Langmuir, Vol.18 (2002), pp.3645-3649.

(15) Torisawa, Y., Kaya, T., Takii, Y., Oyamatsu, D., Nishizawa, M. and Matsue, T., Scanning Electrochemical Microscopy-Based Drug Sensitivity Test for a Cell Culture Integrated in Silicon Microstructures, Anal. Chem., Vol.75 (2003), pp.2154-2158. 
(16) Takii, Y., Takoh, K., Nishizawa, M. and Matsue, T., Characterization of Local Respiratory Activity of PC12 Cells by Scanning Electrochemical Microscopy, Electrochim. Acta, Vol.48 (2003), pp.3381-3385.

(17) Kaji, H., Takoh, K., Nishizawa, M. and Matsue, T., Intracellular $\mathrm{Ca}^{2+}$ Imaging for Micropatterned Cardiac Myocytes, Biotechnol. Bioeng., Vol.81 (2003), pp.748-751.

(18) Kaji, H., Takii, Y., Nishizawa, M. and Matsue, T., Pharmacological Characterization of Micropatterned Cardiac Myocytes, Biomaterials, Vol.24 (2003), pp.4239_ 4244.

(19) Kaji, H., Nishizawa, M. and Matsue, T., Localized Chemical Stimulation to Micropatterned Cells Using Multiple Laminar Fluid Flows, Lab Chip, Vol.3 (2003), pp.208-211.

(20) Chang, J.C., Brewer, G.J. and Wheeler, B.C., Microelectrode Array Recordings of Patterned Hippocampal Neurons for Four Weeks, Biomed. Microdevices, Vol.2 (2000), pp.245-253.

(21) James, C.D., Davis, R., Meyer, A., Turner, A., Turner,
S., Withers, G., Kam, L., Banker, G., Craighead, H., Isaacson, M., Tuner, J. and Shain, W., Aligned Microcontact Printing of Micrometer-Scale Poly-L-Lysine Structures for Controlled Growth of Cultured Neurons on Planar Microelectrode Arrays, IEEE Trans. Biomed. Eng., Vol.47 (2000), pp.17-21.

(22) Lauer, L., Ingebrandt, S., Scholl, M. and Offenhäusser, A., Aligned Microcontact Printing of Biomolecules on Microelectronic Device Surfaces, IEEE Trans. Biomed. Eng., Vol.48 (2001), pp.838-842.

(23) Shin, H., Jo, S. and Mikos, A.G., Biomimetic Materials for Tissue Engineering, Biomaterials, Vol.24 (2003), pp.4353-4364.

(24) Kubota, S., Tashiro, K. and Yamada, Y., Signaling Site of Laminin with Mitogenic Activity, J. Biol. Chem., Vol.267 (1992), pp.4285-4288.

(25) Ennes, H.S., Young, S.H., Raybould, H.E. and Mayer, E.A., Intercellular Communication between Dorsal Root Ganglions Cells and Colonic Smooth Muscle Cells in Vitro, Neuroreport, Vol.8 (1997), pp.733-737. 